\title{
ISJ meeting, Fukui, 17-20 September 2021
}

(c) The Ichthyological Society of Japan 2021

The 55th Annual Meeting of the Ichthyological Society of Japan (ISJ) will be held in Fukui Prefecture, Japan, from 17 to 20 September 2021. Two symposia, entitled "What genomics research can tell us about diversity among fishes: integrative natural history research and future perspectives", and "Studies on the loaches of the genus Lefua; perspectives of evolution, ecology and conservation", will be held during the meeting. At present, details of the meeting venue, schedule and offline/online options are still unclear due to the COVID-19 pandemic. Information regarding registration and mixer fees, and other details will be provided on the ISJ official website (http://www.fish-isj.jp/index-e.html). For further information, please contact the General Affairs Secretary of ISJ, Yusuke Miyazaki (Shiraume Gakuen College, e-mail: miyazaki@shiraume.ac.jp).

\section{Papers published in Japanese Journal of Ichthyology}

The following papers were published in Japanese Journal of Ichthyology Volume 68, Number 1 on 25 April 2021, and English abstracts are available on the ISJ website (http:// www.fish-isj.jp/english/journal.html).

\section{Volume 68, Number 1}

\section{Original Papers}

Morphological characters of the rare velvetfish, Cocotropus keramaensis (Scorpaeniformes: Aploactinidae), including coloration and osteology

Gento Shinohara and Hisashi Imamura

First Japanese record of the snaggletooth Astronesthes formosana (Protacanthopterygii: Stomiidae)

Yudai Koizumi, Hiromitsu Endo and Hisashi Imamura
First record of Lutjanus biguttatus (Perciformes: Lutjanidae) from Japan

Mao Sato, Yuta Inoue, Kazuki Mizowaki, Hirozumi Kobayashi, Rei Matsuo, Taichiro Toyama and Yusuke Hibino

\section{Notes}

Habitat use of the loach Misgurnus anguillicaudatus in a paddy field ditch in wintering

Jyun-ichi Kitamura, Eun-Jin Kim, Jun Nakajima, Kosuke

Takaku and Takahiro Morosawa

Record of Anguilla bicolor pacifica from Iriomote Island, southern Japan

Hiroyuki Inoue, Dai Suzuki, Tadashi Kitano and Hiroyoshi Kohno

Distribution of Anguilla marmorata and habitat water temperatures in Oita Prefecture, Japan

Hiroki Takano and Kazuo Hoshino

Records and genetic characteristics of exotic bitterling, Acleilognathus tabira subspp., from northern Mie Prefecture, Japan

Gen Ito, Jyun-ichi Kitamura, Ryota Noguchi, Nobuaki Nagata and Yasunori Koya

A record of the yellowtail amberjack Seriola aureovittata Temminck and Schlegel, 1845 (Carangidae) from the North Pacific

Toshiaki Shitamitsu, Takashi Yanagimoto and Makoto Okamoto 


\section{Series}

Publisher's Note Springer Nature remains neutral with regard to jurisdictional claims in published maps and institutional affiliations.

Conservation of a local ecosystem: Recovery of the endangered bitterling Acheilognathus typus in Lake Izunuma-Uchinuma after the removal of largemouth bass (Micropterus salmoides)

Yasufumi Fujimoto, Kiyotaka Takahashi, Kentarou Shindou, Kenji Saitoh, Makio Mitsuduka and Tetsuo Shimada 